\title{
Robot-Assisted Nephron-Sparing Surgery for Cystic Nephroma in a Pediatric Patient: A Case Report
}

\author{
Lorenzo Masieri, MD, PhD, ${ }^{1,2}$ Francesco Sessa, MD, ${ }^{2}$ Chiara Cini, MD, ${ }^{1}$ Maurizio Sessa, $\mathrm{PhD}{ }^{3}$ \\ Davide Vanacore, MD, ${ }^{2}$ Giovanni Tasso, MD, ${ }^{2}$ Alessandro Pili, MD, ${ }^{2}$ Simone Sforza, MD, ${ }^{2}$ \\ Isabella Greco, MD, ${ }^{2}$ Riccardo Campi, MD, ${ }^{2}$ Andrea Minervini, MD, PhD, ${ }^{2}$ and Marco Carini, $\mathrm{MD}^{2}$
}

\begin{abstract}
Cystic nephroma is a benign kidney tumor, which presents as a unilateral cystic mass without solid elements. We presented the first case of cystic nephroma treated with robotic nephron-sparing surgery in a pediatric patient. The procedure adopted was the robot-assisted simple enucleation of the lesion, without arterial clamping.
\end{abstract}

Keywords: kidney neoplasms, child, robotic surgical procedures, robotics, humans

\section{Introduction and Background}

C YSTIC NEPHROMA is a rare benign cystic neoplasm, almost uniformly unilateral, encountered in both children and adults. Also known as benign multilocular renal cyst, it is characterized by solitary, well-circumscribed, multiseptate noncommunicating, fluid-filled loculi, surrounded by a thick fibrous capsule. Usually, it compresses the adjacent renal parenchyma. ${ }^{1}$ Patients typically present an abdominal mass with or without abdominal pain and hematuria. ${ }^{2}$ No guidelines, as well as consensus or position paper, exist on the procedure to treat this condition. ${ }^{3}$ If preoperative radiological study supports the appearance of a benign tumor, nephronsparing surgery (NSS) can be an appropriate choice and should be considered first if preoperative radiologic study strongly supports the appearance of a benign tumor and is technically feasible. ${ }^{4}$ Despite robot-assisted NSS dramatical increase during last years, ${ }^{5}$ to our knowledge the use of this approach in pediatric surgery for exeresis of cystic nephroma was never described before.

\section{Presentation of Case}

In February 2016, a 9-year-old patient was admitted to our department in suspicion of acute appendicitis. Physical ex- amination was unremarkable except for right-flank pain and fever. Biochemical parameters and renal function were within normal ranges. Urinalysis was negative for red blood cells. The ultrasonography examination of abdomen showed a cystic mass on the upper pole of the left kidney; the MRI confirmed the presence of a $23 \times 19 \mathrm{~mm}$ relatively wellcircumscribed lesion (Fig. 1A, B). According to the up-todate evidences, a conservative NSS robot-assisted procedure was performed (Supplementary Video S1); we adopted the da Vinci Xi robotic system with three-arm configuration and $30^{\circ}$ laparoscopic optical (Fig. 1C, D). Pneumoperitoneum inducted after an umbilical mini-open access with $8.5 \mathrm{~mm}$ trocar and patient in right lateral decubitus. Peritoneum incised along Toldt's line, the bowel medialized and the Gerota's fascia opened, the renal blood vessels and an inferior polar pedicle were identified. The intraoperative ultrasonography defined the margins of tumor; the excision template was marked with cautery 1 to $2 \mathrm{~mm}$ away from the lesion. The lesion enucleation by blunt dissection led to an edge of dissection free of renal parenchyma (Fig. 2). The arterial clamping was not necessary. Hemostasis was realized with 4-0 monofilament transfixed stitches and opposition of hemostatic material. ${ }^{1}$ Operative time was 110 minutes. Estimated blood loss was $30 \mathrm{~mL}$. The catheter and the pararenal drainage were removed on the first and second postoperative day,

\footnotetext{
${ }^{1}$ Department of Pediatric Surgery, Pediatric Urology Unit, Anna Meyer Children's Hospital, Florence, Italy.

${ }^{2}$ Department of Urology, Careggi Hospital, University of Florence, Florence, Italy.

${ }^{3}$ Department of Experimental Medicine, Section of Pharmacology "L. Donatelli," Second University of Naples, Naples, Italy.
} 
FIG. 1. Case presentation. (A, B) MRI preoperatory imaging. Arrows indicate the mass on upper pole of the left kidney. Diameter of lesion $23 \times 19 \mathrm{~mm}$. (C, D) Trocar positioning according to patient's anatomy for the optimal triangulation toward the upper pole: an $8.5 \mathrm{~mm}$ umbilical trocar for the camera; two $8 \mathrm{~mm}$ ports for the robotics instruments and a $5 \mathrm{~mm}$ trocar for the assistant.
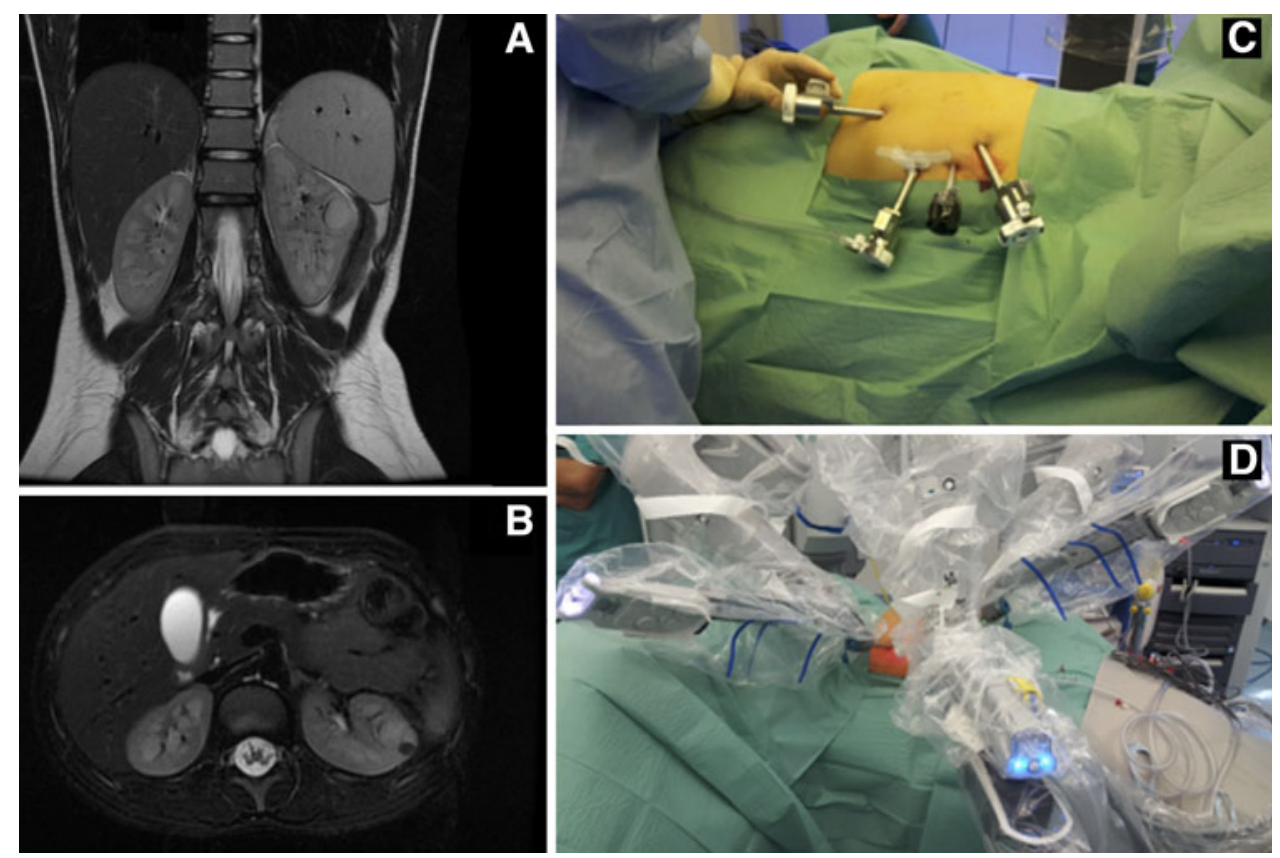

respectively. Hospital stay was 4 days. No intraoperative complications occurred. No medical or surgical complication occurred during the 2 years follow-up. The histopathological examination confirmed the diagnosis of cystic nephroma with negative margin of resection.

\section{Discussion and Literature Review}

Multilocular cystic nephroma can occur in children and adults. ${ }^{1}$ Most pediatric cases are seen in girls older than 4 years old or in boys younger than 4 years old. ${ }^{6}$ Depending on the size, the lesion can be palpable and painful, hematuria and fever may be present. ${ }^{7}$ In 1989, Joshi and Beckwith replaced the Boggs and Kimmelstiel's criteria for the diagnosis of cystic nephroma. ${ }^{8}$ The differential diagnosis of a cystic renal mass varies in adults and children, and may include polycystic kidney, nephroblastomas, Wilms' tumor, hydronephrotic kidney, mesoblastic nephroma, and cystic renal cell carcinoma. Preoperative imaging and macroscopic examination are not completely reliable to differentiate it from a malignancy; therefore, the elective treatment is surgery as only the histological report confirms the diagnosis.

Therefore, whenever suspicion of this clinical condition exists, surgical intervention represents the elective treatment and only the histological examination can confirm the diagnosis. In our case, we decided to perform nephron-sparing surgery after careful consideration of the clinical case and the MRI findings, which allowed us to preoperatively consider
FIG. 2. (A) Ultrasonographic assessment of lesion edges. (B) Marking margins of excision for enucleation by electrocautery. (C) Blunt dissection of the cleavage plane between the mass and the healthy renal parenchyma. (D) Suture of margins of enucleation with 4-0 continuous monofilament.

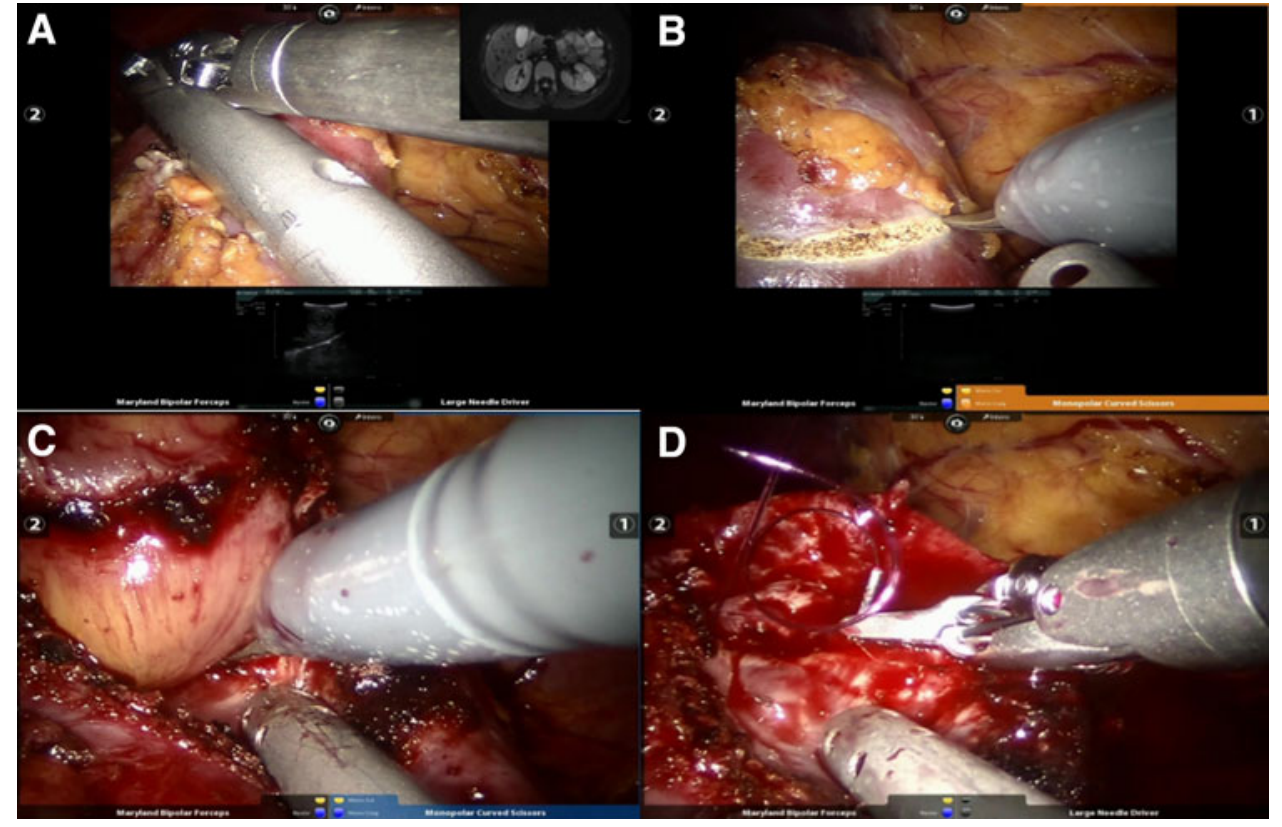


the renal mass as a cystic nephroma. The clinical presentation in addition to the imaging findings, which suggested the presence of a benign cystic nephroma, supported our choice to be conservative. In particular, our decision on the type of surgical strategy was founded on the following elements: a) the absence of communication between the cysts and renal parenchyma; $b$ ) the appearance of isolated and noncommunicating loculi, filled with a citrine-clear fluid; and c) the regularity of the residual kidney with no nephronic differentiation in the septa of cysts. ${ }^{9}$ Among all alternatives for NSS, the robotic assistance offers a better control of the operatory field and target structures to a three-dimensional vision associated with the "EndoWrist" technology. ${ }^{10}$ This advantage grants reduction of operative time and peri- and postoperatory complications, leading to an early recovery and a shorter hospital stay. Similar outcomes have been widely described in adults undergoing robotic NSS for the treatment of renal masses; nevertheless, we share our experience adopting this technique on an interesting pediatric case. Of note, the robotic assistance may significantly improve the quality of both tumor enucleation and renal reconstruction as compared with standard laparoscopic surgery, leading to a potentially higher use of this technology in the future for the treatment of selected localized renal masses in pediatric patients.

\section{Conclusion}

We report an interesting case of cystic nephroma as an unusual differential diagnosis of tumors. Even if the histology only can provide the definite diagnosis, the combination of clinical, biochemical, and radiological features is a pivotal to understand the lesion behavior. This is the first case of cystic nephroma treated with robotic NSS in a pediatric patient. We cannot exclude that in the future robotic nephronsparing technique could represent an elective technique for the treatment of this rare clinical condition.

\section{Acknowledgment}

The authors declare no funding sources or other external assistance.

\section{Authors' Contributions}

C.C., S.F., L.M., V.D., L.L., T.M., and M.L. performed surgery; M.S. wrote and critically reviewed the article. All authors read and approved the final article.

\section{Disclosure Statement}

The authors declare no conflict of interest.

\section{References}

1. Sethi S, Agarwal S, Dev G, Bhatnagar D, Gupta S. Cystic nephroma-An unusual cystic renal lesion. Indian J Pathol Microbiol 1992;35:255-260.

2. Truong LD, Choi YJ, Shen SS, Ayala G, Amato R, Krishnan B. Renal cystic neoplasms and renal neoplasms associated with cystic renal diseases: Pathogenetic and molecular links. Adv Anat Pathol 2003;10:135-159.

3. Montironi R, Mazzucchelli R, Lopez-Beltran A, Martignoni G, Cheng L, Montorsi F, Scarpelli M. Cystic nephroma and mixed epithelial and stromal tumour of the kidney: Opposite ends of the spectrum of the same entity? Eur Urol 2008;54:1237-1246.

4. Cozzi F, Schiavetti A, Morini F, Zani A, Gambino M, Donfrancesco C, Cozzi DA. Renal function adaptation in children with unilateral renal tumors treated with nephron sparing surgery or nephrectomy. J Urol 2005;174:14041408.

5. Dong B, Wang Y, Zhang J, Fu Y, Wang G. Multilocular cystic nephroma treated with laparoscopic nephronsparing surgery: A case report. Can Urol Assoc J 2014;8: E545-E547.

6. Bisceglia M, Galliani CA, Senger C, Stallone C, Sessa A. Renal cystic diseases: a review. Adv Anat Pathol 2006;13: 26-56.

7. Ashley RA, Reinberg YE. Familial multilocular cystic nephroma: A variant of a unique renal neoplasm. Urology 2007;70:179, e9-e10.

8. Boggs LK, Kimmelstiel P. Benign multilocular cystic nephroma: Report of two cases of so-called multilocular cyst of the kidney. J Urol 1956;76:530-541.

9. Joshi VV, Beckwith JB. Multilocular cyst of the kidney (cystic nephroma) and cystic, partially differentiated nephroblastoma. Terminology and criteria for diagnosis. Cancer 1989;64:466-479.

10. Serni S, Vittori G, Frizzi J, Mari A, Siena G, Lapini A, Carini M, Minervini A. Simple enucleation for the treatment of highly complex renal tumors: Perioperative, functional and oncological results. Eur J Surg Oncol 2015;41:934-940.

Address correspondence to: Lorenzo Masieri, MD Department of Pediatric Surgery Pediatric Urology Unit Anna Meyer Children's Hospital Viale Pieraccini 24 Florence 50139 Italy

E-mail: lorenzo.masieri@meyer.it

\begin{tabular}{|l|}
\hline Abbreviations Used \\
MRI $=$ magnetic resonance imaging \\
$\mathrm{NSS}=$ nephron-sparing surgery
\end{tabular}

Cite this article as: Masieri L, Sessa F, Cini C, Sessa M, Vanacore D, Tasso G, Pili A, Sforza S, Greco I, Campi R, Minervini A, Carini M (2019) Robot-assisted nephronsparing surgery for cystic nephroma in a pediatric patient: a case report, Journal of Endourology Case Reports 5:1, 7-9, DOI: 10.1089/cren.2018.0084. 